\title{
Qualitative Analysis of High-Growth Companies
}

\author{
Patrik Frei ${ }^{\star}$
}

\begin{abstract}
Investing in high-growth companies carries substantial risks. This has been experienced by many investors in the past several years. Despite these negative experiences, however, there are numerous examples of companies that grew from small start-ups to established, cash-flow positive companies. The assessment of a company based on qualitative factors (soft factors) provides a good basis to identify and choose potential winners. The assessment is also used for the financial valuation of a high-growth company.
\end{abstract}

Keywords: Financial valuation · Forward looking assessment · Growth companies · Management team ·

Start-ups · Strategic alliances

Do not underestimate the importance of getting a proper financial valuation for a high growth enterprise. To obtain seed funding or later-stage venture capital, expand a business, or for a merger/acquisition, a company needs to be valued.

The value of a company directly determines the size of the portion of equity a particular investment sum will purchase. It is crucial for company management as well as investors or collaborative partners with an equity stake, to have a good understanding of what a company is worth.

Venture Valuation has been exclusively conducting independent, third party valuations of start-up high-growth technology and biotechnology companies for over five years now. The approach utilized by Venture Valuation is different from the methods generally used by accounting and auditing companies which primarily use past performance to determine current value. For high-growth companies there is often not a long history to help determine that value. Also, asset valuation or a value based on past and current earnings does not make sense as there are usually few tangible assets in the company and no earnings. Nevertheless, these knowledge-driven companies are generally worth more than zero.
The Venture Valuation approach determines current value based on future potential. To truly understand the potential of a given company, it is crucial to carefully analyze the underlying business model of a company. It is the 'soft' (as opposed to hard financial) factors, such as strength of management, innovative technology, favorable market environment, that ultimately determine a company's success in the future and that form the basis for a solid valuation. In the following we try to provide a framework - the Fig. gives an overview of this model - to conduct such an analysis.
One has to make sure to analyze and understand these soft factors and use them to determine the risk factor associated with each company with regard to its future earning potential. Ultimately the determined risk factor directly influences the discount rate, which is used for the valuation of an individual company.

This forward-looking assessment of a company's earnings potential is based on 1) management, 2) market environment and 3) sciences and technology. Furthermore, the stage of the company also has a direct influence on the risk profile of the company.

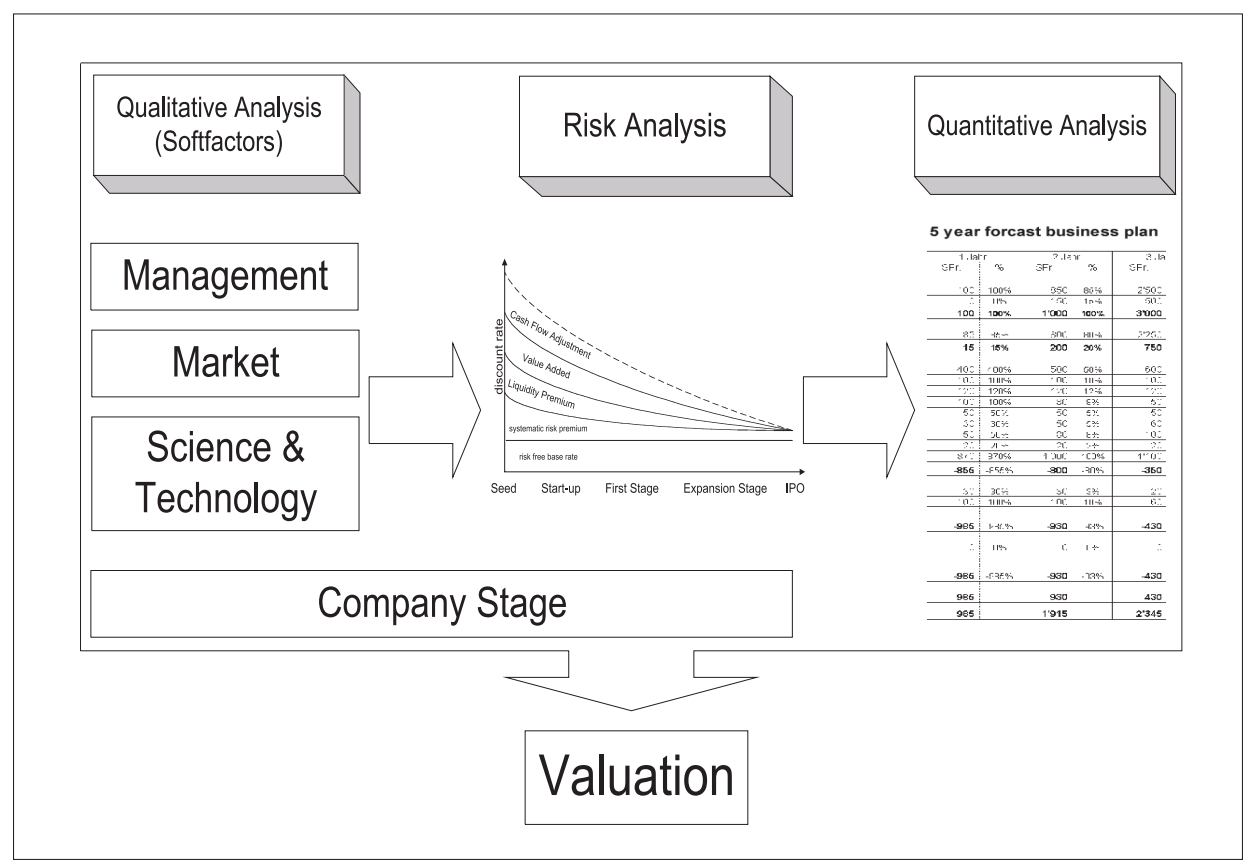

${ }^{*}$ Correspondence: P. Frei

Lic. oec. HSG

Partner + CEO

Venture Valuation AG

Badenerstr. 18

$\mathrm{CH}-8004$ Zürich

Tel.: +41433218660

E-Mail: patrik.frei@venturevaluation.ch

www.venturevaluation.ch 
Table 1. Financing stages

\begin{tabular}{|c|c|}
\hline Phase & Characterization \\
\hline Seed Stage & $\begin{array}{l}\text { - Only an idea exists } \\
\text { - Business Plan is in development } \\
\text { - A possible first prototype is available } \\
\text { - There is a clear intention to found a company }\end{array}$ \\
\hline Start-up Stage & $\begin{array}{l}\text { - The company has been successfully founded } \\
\text { - The management team is completed } \\
\text { - First 'Proof of Concept' of product } \\
\text { - Preparation for production and customer contacts }\end{array}$ \\
\hline First Stage & $\begin{array}{l}\text { - Marketing is a main focus } \\
\text { - Production and market introduction } \\
\text { - 'Proof of Market' } \\
\text { - First revenues, negative cash flow }\end{array}$ \\
\hline Second Stage & $\begin{array}{l}\text { - Development of home market } \\
\text { - Risk is decreasing rapidly } \\
\text { - Market success, break-even }\end{array}$ \\
\hline Later Stage & $\begin{array}{l}\text { - Diversification } \\
\text { - Potential restructuring } \\
\text { - Possibility for debt financing } \\
\text { - Preparation for IPO within one year possible }\end{array}$ \\
\hline
\end{tabular}

Table 2. Drug discovery stages compared with company stages

\section{Drug discovery stages}

Generating Leads

Optimizing Leads/Pre-clinical

Clinical Trials: Phase I

Clinical Trials: Phase II

Clinical Trials: Phase III

Submission and regulatory approval

\section{Company stages}

Seed stage

Start-up stage

First growth stage

Second growth stage

Later stage

IPO

\section{Management}

A face-to-face evaluation of the core management team is essential. Every company sooner or later faces crises and challenges. An excellent management team can get a company over almost any hurdle or difficulty it may face.

Similarly, no matter how good a business plan or how elaborate financial projections of a company, a management team that lacks vision or ultimate commitment will not succeed. A good management team is not always evident in a business plan. At Venture Valuation we came across a company that offered a very short and unsophisticated business plan. But when the management team turned up, it was clear that they were very focused on bringing the product to the market and that they had made the decision to not spend a lot of time working on a business plan, and to instead invest their time in rolling out their product.

In this case the founders had an exact vision of where they wanted to go and how they wanted to reach their goals. It simply was not well communicated in the business plan.
When evaluating a management team, we look for complementary teams and skills as well as the track record of the team as a whole and the individual team members and how this can help to achieve the challenges of the future. It is also important how the employees are involved in the company, whether they are thinking like owners or simply following orders. An employee stock option plan, for example, is usually a good sign that the company is committed to attracting and retaining top talent. Another important factor we consider is the degree of commitment and expertise that the board of directors as well as a scientific advisory board brings to a company.

\section{Market}

If there is no market for a product then even outstanding technology will not guarantee success. Therefore we systematically analyze the environment in which the product or service is positioned. In our experience, the five forces concept by Michael Porter is a good methodology for the market assessment.

The first step is to check what kind of substitute could satisfy the same market need. Next the competition is analyzed. We consid- er the intensity of rivalry among existing players and also determine the barriers of entry for new competitors. We believe it to be very important to get a feeling for the current and future market environment to determine the likelihood of success. Additionally the bargaining power of suppliers and buyers are taken into consideration. Further criteria include market size and growth potential.

\section{Technology}

On the technology side we most importantly assess the competitive advantages the company has with its technology and how sustainable it is. One important part is the assessment of intellectual property rights and the depth of coverage the patents provide. Depending on the nature of the business, technology can be very important (i.e. biotechnology).

Furthermore the strategic alliances and partnerships a company has been able to build can also play a very important part in the overall evaluation.

\section{Financing Stage}

Another main factor to evaluate the risk factor of a company is the financing stage. It can provide information about the development phase. In general, the risk decreases disproportionate to the successful development of a company. Table 1 gives an overview of typical factors that characterize the different financing stages.

Biotechnology companies represent a significant portion of high-growth companies. However, their financing and development stages differ from other typical highgrowth ventures, primarily as the development times for new drugs are much longer than for a consumer product. Thus, the typical categorization used for drug discovery biotechnology companies is based on the stage of product development. Table 2 provides guidelines on how to match the drug discovery stages with the company stages. The most advanced product should be taken into consideration as the benchmark when a company possesses a portfolio of such products.

Based on the proposed assessment model, the risk analysis can be performed. Together with the quantitative analysis, a valuation can be determined. Since the valuation for highgrowth technology companies depends on multiple factors and really cannot be pinned down to one single method, several different methods are used for the calculation.

At Venture Valuation, our view of valuation is not what has happened in the past but rather what the future could bring.

Received: October 21, 2004 